\title{
ИДЕНТИФИКАЦИЯ МЕЖВИДОВЫХ ГИБРИДОВ АРХАРА (Ovis ammon) И ДОМАШНЕЙ ОВЦЫ (Ovis aries) РАЗНЫХ ПОКОЛЕНИЙ ПО ПОКАЗАТЕЛЯМ ЭКСТЕРЬЕРА*
}

\author{
Б.С. ИОЛЧИЕВ ${ }^{凶}$, Н.А. ВОЛКОВА, В.А. БАГИРОВ, Н.А. ЗИНОВЬЕВА
}

При создании новых пород и селекционных форм используют различные методы разведения, в том числе отдаленную гибридизацию. Использование генетических ресурсов архара (Ovis ammon) для получения межвидовых гибридов с домашней овцой (Ovis aries) перспективно для создания новых селекционных форм и изучения биологических особенностей отдельных видов рода Ovis. При этом требуется идентификация полученных межвидовых гибридов. Наряду с молекулярным генотипированием таких животных представляет интерес использование информативных фенотипических показателей, характерных для гибридных особей. В настоящей работе впервые представлены результаты дифференциации разных поколений гибридов от спаривания архара с овцами романовской породы и исходных родительских форм по экстерьерным признакам. Подтверждена возможность использования экстерьерных показателей для предварительной идентификации гибридных особей без проведения дорогостоящих геномных исследований. При гибридизации во второй и следующих генерациях происходило расщепление гибридных особей по генотипу и фенотипу. Целью работы была сравнительная характеристика морфометрических показателей чистопородных овец романовской породы и их межвидовых гибридов с архаром для выявления информативных экстерьерных показателей, идентифицирующих гибридных особей. Исследования проводили на чистопородных романовских ягнятах $(n=20)$ и межвидовых гибридах $1 / 2$ романовская порода $1 / 2$ apxap $(F 1, n=12), 3 / 8$ романовская порода $5 / 8$ apхар $(F 3, n=17), 7 / 16$ романовская порода $9 / 16$ apхар $(\mathrm{F} 4, n=18)$ (физиологический двор ФИЦ ВИЖ им. Л.К. Эрнста, 2019-2020 годы). Выполняли следующие промеры животных: высота в холке, высота в крестце, высота спины, косая длина туловища, длина тела, ширина груди, ширина крестца, глубина груди, обхват пясти. Линейные промеры снимали в возрасте 6, 42 сут и 3 мес с помощью мерной ленты, рулетки и мерного циркуля. Животных взвешивали на электронных весах. Для оценки развития ягнят на основании весовых и линейных промеров рассчитывали индексы телосложения: индекс длинноногости, индекс растянутости, индекс перерослости, грудной индекс, индекс костистости, индекс массы тела. Для статистического анализа использовали программное обеспечение SPSS v.23. В качестве фактора, влияющего на линейные промеры, была выбрана породная принадлежность особей. Гибридные животные в возрасте 3 мес по сравнению с чистопородными особями романовской породы имели более высокий индекс длинноногости, что характерно для архара. Преимущество гибридов F1, F3 и F4 над чистопородными животными по этому показателю составило соответственно 4, 8 и $2 \%$. При этом гибриды F1, F3 и F4 имели более сжатую прямоугольную форму туловища, поэтому уступали чистопородные ягнятам по индексу растянутости соответственно на 18, 22 и 18 \% (p < 0,05). Были установлены различия между чистопородными и гибридными животными по линейным и широтным промерам. Преимущество чистопородных овец над гибридами F1, F3 и F4 по косой длине туловища составило 18, 20 и $14 \%$, по ширине груди $-35,33$ и $20 \%$ (р < 0,05), по глубине груди $-17,19$ и 7 \% (p < 0,05). Иерархическая классификация гибридов и чистопородных животных по экстерьерным признакам показала, что межвидовые гибриды с кровностью по архару $1 / 2$ и $5 / 8$ локализовались в одном кластере. Гибриды с $9 / 16$ кровностью по архару и чистопородные животные романовской породы образовывали отдельные кластеры. Полученные результаты подтверждают, что экстерьерные показатели могут быть использованы для предварительной идентификации гибридных особей, сокращая в ряде случаев затраты на геномные исследования.

Ключевые слова: межвидовые гибриды, Ovis ammon, apxap, Ovis aries, домашняя овца, романовская порода, экстерьер.

Для анализа и оценки биологического разнообразия популяций, а также идентификации пород используются различные методы генотипического и фенотипического анализа $(1,2)$. Решение проблемы сохранения биоразнообразия диких и генофонда сельскохозяйственных животных требует комплексного подхода с применением современных и классических

\footnotetext{
* Работа выполнена в рамках государственного задания, рег. № AAAA-A18-118021590132-9 (получение и изучение межвидовых гибридов $\mathrm{F}_{3}$ и F4) и при финансовой поддержке РНФ, грант № 18-16-00079 (получение и изучение межвидовых гибридов F1).
} 
методов (3).

Генетическая изменчивость позволяет расширить ареал пород посредством их интродукции в новую природно-климатическую зону и служит основой для создания новых пород, в том числе адаптированных к локальным условиям $(4,5)$.

Для описания породных особенностей овец используют морфометрические методы (6-8). Морфологические параметры наряду с генетическими применяются для дифференциации популяций и пород $(9,10)$. В настоящее время характеристика генетической изменчивости сельскохозяйственных животных, в том числе овец, осуществляется на основе анализа микросателлитных маркеров (11).

Морфометрические исследования имеют важное значение для характеристики экстерьера, выявления различий между породами (12), оценки телосложения животных и хозяйственно полезных признаков (1315). На основании морфометрических данных рассчитывают индексы, по которым можно определить тип телосложения (16). Морфометрические параметры также применяются для косвенной оценки живой массы и направления продуктивности животных (17), отбора и подбора по экстерьеру (18). Изучение морфометрических параметров в течение длительного периода позволяет дать характеристику структуры породы и популяции, а также направления селекции за определенный промежуток времени (19).

В ряде исследований показана тесная корреляционная взаимосвязь некоторых линейных промеров экстерьера с живой массой у овец (20-22). Показатель живой массы зависит от многочисленных факторов, в том числе породы, возраста, условий содержания, кормления (23-26). Число ягнят в помете отрицательно коррелирует с их живой массой и влияет на сохранность до отъема (27).

В настоящей работе впервые представлены результаты дифференциации по экстерьерным признакам межвидовых гибридов разных поколений от спаривания архара с овцами романовской породы и исходных родительских форм. Подтверждена возможность использования экстерьерных показателей для предварительной идентификации гибридных особей без проведения дорогостоящих геномных исследований. При гибридизации во второй и следующих генерациях происходило расщепление гибридных особей по генотипу и фенотипу.

Целью работы была сравнительная характеристика морфометрических показателей чистопородных овец романовской породы и их межвидовых гибридов с архаром для выявления информативных экстерьерных показателей, идентифицирующих гибридных особей.

Методика. Исследования проводили на чистопородных романовских ягнятах $(n=20)$ и межвидовых гибридах $1 / 2$ романовская порода $1 / 2$ apхар $\left(\mathrm{F}_{1}, n=12\right), 3 / 8$ романовская порода $5 / 8$ apхар $(\mathrm{F} 3, n=17), 7 / 16$ романовская порода $9 / 16$ архар $\left(\mathrm{F}_{4}, n=18\right)$ (физиологический двор ФИЦ ВИЖ им. Л.К. Эрнста, 2019-2020 годы). Содержание овец было стойлово-пастбищным. С мая по октябрь животных выпускали на искусственные и естественные пастбища с использованием электропастуха. В зимний период овцы находились в загонах под навесом на глубокой подстилке. В зимний суточный рацион овец входили сено $(2,0$ кг), концентраты $(0,35$ кг), сенаж (2,5 кг), соль поваренная (15 г), в летний - пастбищная трава и поваренная соль (15 г). В период окота овцематки с ягнятами содержались в группах в зависимости от возраста ягнят (не более 15 маток в группе с ягнятами до 1-недельного возраста). Далее матку с подросшим ягненком помещали в отдельную клетку на 5-6 сут. В тех случаях, когда матка плохо 
принимала своего ягненка, ягненок не узнавал мать или был очень слабым, их содержали в индивидуальной клетке более длительное время. При этом внимательно следили за кормлением ягненка и при необходимости через каждые 2-3 ч подсаживали его под матку.

Морфометрию животных проводили по следующим промерам: высота в холке (BХ, см), высота в крестце (BK, см), высота спины (BC, см), косая длина туловища (КДТ, см), длина тела (ДТ, см), ширина груди (ШГ, см), ширина крестца (ШК, см), глубина груди (ГГ, см), обхват пясти (ОП, см). Линейные промеры снимали в возрасте 6, 42 сут и 3 мес с помощью мерной ленты, рулетки и мерного циркуля. Животных взвешивали на электронных весах. Для оценки развития животных на основании весовых и линейных промеров рассчитывали индексы телосложения: индекс длинноногости, индекс растянутости, индекс перерослости, грудной индекс, индекс костистости, индекс массы тела.

Для статистического анализа использовали программное обеспечение SPSS v.23 («IBM», США). Обработку полученных данных проводили посредством дисперсионного анализа. В качестве фактора, влияющего на линейные промеры ягнят, учитывали породную принадлежность особей. Вычисляли средние арифметические значения $(M)$ и стандартные ошибки средних $( \pm \mathrm{SEM})$. Для выявления статистической значимости различий средних величин использовали $t$-критерий Стьюдента. Проводили парные сравнения каждого показателя в зависимости от учитываемых факторов. Показатели индексов телосложения использовали для иерархической классификации исследуемых групп. На основе полученных данных строили дендрограмму, применяя метод межгрупповой связи и евклидовых расстояний.

Результаты. С помощью дисперсионного анализа морфометрических данных было установлено статистически значимое влияние породы и вида животных на высоту в холке, высоту и ширину в крестце, высоту спины, обхват пясти, живую массу ( $<<0,001)$, индексы перерослости $(\mathrm{p}<0,01)$, растянутости и массы тела $(\mathrm{p}<0,05)$ (табл. 1).

1. Результаты однофакторного дисперсионного анализа влияния генотипа на морфометрические параметры у ягнят романовской породы (Ovis aries) и гибридов разной кровности от спаривания романовских овец с архаром $(O$. ammon) (ФИЦ животноводства - ВИЖ им. академика Л.К. Эрнста, 2019-2020 годы)

\begin{tabular}{|c|c|c|c|}
\hline Зависимая переменная & $\mathrm{df}$ & $F$ & $\mathrm{p}$ \\
\hline Высота в холке, см & 3 & 5,27 & 0,006 \\
\hline Высота в крестце, см & 3 & 5,66 & 0,004 \\
\hline Высота спины, см & 3 & 6,64 & 0,002 \\
\hline Ширина в крестце, см & 3 & 9,53 & 0,000 \\
\hline Обхват пясти, см & 3 & 7,11 & 0,001 \\
\hline Косая длина туловища, см & 3 & 9,88 & 0,000 \\
\hline Глубина груди, см & 3 & 3,58 & 0,030 \\
\hline Живая масса, кг & 3 & 4,00 & 0,020 \\
\hline Индекс растянутости & 3 & 3,18 & 0,030 \\
\hline Индекс перерослости & 3 & 5,60 & 0,003 \\
\hline Индекс массы тела & 3 & 2,77 & 0,050 \\
\hline
\end{tabular}

В возрасте 6 сут гибридные животные преимущественно уступали чистопородным сверстникам по живой массе и ряду линейных промеров (табл. 2). Значительные различия были установлены между чистопородными животными романовской породы и межвидовыми гибридами $\mathrm{F}_{1} \mathrm{c}$ кровностью $1 / 2$ по архару. Преимущество чистопородных животных над гибридами $\mathrm{F}_{1}$ по живой массе, ВХ, ВК, ВС, КДТ, ОП составило соответственно 25, 8, 10, 10, 9 и $18 \%$ (p < 0,05). Различия по этим показателям 
между чистопородными животными и гибридами более поздних поколений $\mathrm{F}_{3}$ и $\mathrm{F} 4$ нивелировались с увеличением кровности по романовской породе. При этом по длине тела и ширине крестца гибриды превосходили своих чистопородных аналогов. Преимущество гибридов $\mathrm{F}_{1}, \mathrm{~F}_{3}$ и $\mathrm{F}_{4}$ над чистопородными животными по ДТ составило 12, 17 и $16 \%$ (p < 0,01), по ШК - 35, 50 и $60 \%(\mathrm{p}<0,01)$.

2. Возрастная динамика линейных промеров и живая масса ягнят романовской породы (Ovis aries) (POM) и гибридов разной кровности от спаривания ро-

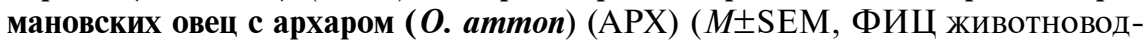
ства - ВИЖ им. академика Л.К. Эрнста, 2019-2020 годы)

\begin{tabular}{|c|c|c|c|c|}
\hline \multirow{2}{*}{ Показатель } & \multicolumn{4}{|c|}{ Генотип } \\
\hline & POM & $1 / 2 \mathrm{POM}^{1 / 2} \mathrm{APX}$ & $3 / 8$ POM 5/8 APX & 7/16 POM 9/16 APX \\
\hline \multicolumn{5}{|c|}{ Возраст 6 с у т } \\
\hline Высота в холке, см & $38,25 \pm 1,56$ & $35,33 \pm 0,84$ & $37,88 \pm 0,85^{*} \mathrm{c}$ & $39,14 \pm 0,72 * \mathrm{c}$ \\
\hline Высота в крестце, см & $37,75 \pm 0,53^{*} \mathrm{c}$ & $34,12 \pm 0,83$ & $37,72 \pm 0,83^{*} \mathrm{c}$ & $38,23 \pm 0,71^{* \mathrm{c}}$ \\
\hline Высота спины, см & $37,75 \pm 0,15^{*} \mathrm{c}$ & $33,97 \pm 0,82$ & $37,88 \pm 0,83 * \mathrm{c}$ & $38,52 \pm 0,71^{*} \mathrm{c}$ \\
\hline Косая длина туловища, см & $28,00 \pm 1,95$ & $25,45 \pm 1,05$ & $28,83 \pm 1,06$ & $28,18 \pm 0,90^{*} \mathrm{c}$ \\
\hline Длина тела, см & $28,00+1,49$ & $31,45+0,80$ & $32,72+0,81^{* a}$ & $32,30+0,69 * a$ \\
\hline Глубина груди, см & $13,00 \pm 0,69$ & $12,50 \pm 0,37$ & $12,85 \pm 0,37$ & $13,66 \pm 0,32$ \\
\hline Ширина груди, см & $6,50 \pm 0,79$ & $6,75 \pm 0,43$ & $7,50 \pm 0,43$ & $7,92 \pm 0,37$ \\
\hline Ширина крестца, см & $5,50 \pm 0,68$ & $7,43 \pm 0,37^{* a}$ & $8,25 \pm 0,37^{* a}$ & $8,77 \pm 0,31^{* a c}$ \\
\hline Обхват пясти, см & $5,75 \pm 0,14^{*}$ bcd & $4,70 \pm 0,07$ & $5,05 \pm 0,07^{*} \mathrm{c}$ & $5,05 \pm 0,06^{*} \mathrm{c}$ \\
\hline Живая масса, кг & $3,95 \pm 0,37$ & $2,98 \pm 0,20$ & $3,69 \pm 0,20$ & $4,05 \pm 0,17^{*} \mathrm{c}$ \\
\hline \multicolumn{5}{|c|}{ Возраст 42 сут } \\
\hline Высота в холке, см & $44,90 \pm 1,02$ & $43,50 \pm 1,18$ & $43,75 \pm 1,40$ & $47,78 \pm 0,97^{*} \mathrm{~cd}$ \\
\hline Высота в крестце, см & $44,55 \pm 0,77$ & $42,93 \pm 0,88$ & $44,33 \pm 1,05$ & $47,15 \pm 0,73^{*}$ acd \\
\hline Высота спины, см & $45,07 \pm 0,90$ & $43,00 \pm 1,02$ & $44,91 \pm 1,22$ & $48,30 \pm 0,855^{*}$ acd \\
\hline Косая длина туловища, см & $38,72 \pm 0,70^{*} \mathrm{bcd}$ & $31,87 \pm 0,79$ & $30,83 \pm 0,95$ & $33,32 \pm 0,66$ \\
\hline Длина тела, см & $37,88 \pm 1,00$ & $40,00 \pm 1,14$ & $41,00 \pm 1,36$ & $41,26 \pm 0,95^{* a}$ \\
\hline Глубина груди, см & $19,03 \pm 2,47$ & $15,62 \pm 2,83$ & $15,33 \pm 3,37$ & $17,80 \pm 2,35$ \\
\hline Ширина груди, см & $13,22 \pm 2,91$ & $8,56 \pm 3,32$ & $8,83 \pm 3,96$ & $10,56 \pm 2,76$ \\
\hline Ширина крестца, см & $10,35 \pm 0,55$ & $9,62 \pm 0,63$ & $10,75 \pm 0,75$ & $11,07 \pm 0,52$ \\
\hline Обхват пясти, см & $5,50 \pm 0,25$ & $5,18 \pm 0,29$ & $5,33 \pm 0,35$ & $5,67 \pm 0,24$ \\
\hline Живая масса, кг & $9,06 \pm 0,51$ & $7,82 \pm 0,58$ & $7,58 \pm 0,69$ & $9,04 \pm 0,48 * \mathrm{~cd}$ \\
\hline
\end{tabular}

П р и м е ч а н и е. Обозначение сравниваемых групп животных: a - романовская порода; $b-$ гибриды ${ }^{7} / 16$ POM 9/16 APX; c - гибриды $1 / 2$ POM 1/2 APX; d - гибриды $3 / 8$ POM 5/8 APX.

* Различия между сравниваемыми группами статистически значимы при р $<0,05$.

В возрасте 42 сут преимущество чистопородных животных над гибридами всех исследованных поколений сохранялось только по живой массе, КДТ, ШГ и ГГ (см. табл. 2). Различия между чистопородными овцами и гибридами $\mathrm{F}_{1}, \mathrm{~F}_{3}$ и $\mathrm{F}_{4}$ по живой массе составили соответственно 14, 16 и $0,2 \%(\mathrm{p}<0,05)$, по КДТ - 18, 20 и $14 \%(\mathrm{p}<0,05)$, по ШГ- 35, 33 и $20 \%(\mathrm{p}<0,05)$, по ГГ $-17,19$ и $7 \%(\mathrm{p}<0,05)$. Вместе с тем гибридные животные, как и в 6-суточном возрасте, превосходили чистопородных сверстников по длине тела. По этому показателю превышение возрастало с увеличением кровности по архару у гибридов $\mathrm{F}_{1}, \mathrm{~F}_{3}$ и $\mathrm{F}_{4}$, составив соответственно 6, 8 и $9 \%(\mathrm{p}<0,05)$.

Различия между чистопородными и гибридными животными по показателям ВС, ВХ и ВК варьировали в зависимости от кровности гибридов по исходным родительским формам. Если гибриды $F_{1}$ и $F_{3}$ уступали по этим линейным промерам чистопородным животным, то гибриды $\mathrm{F} 4$, наоборот, превосходили их.

Вариабельность различий по линейным промерам между чистопородными животными и гибридами разных поколений отмечалась и в возрасте 3 мес (рис. 1). Чистопородные животные по всем промерам превосходили гибриды $\mathrm{F}_{1}$ и $\mathrm{F}_{3}$, однако уступали особям $\mathrm{F}_{4}$ по этим показателям, за исключением КДТ и живой массы.

Для оценки развития чистопородных и гибридных животных были рассчитаны индексы телосложения. В возрасте 6 сут гибридные животные 
по сравнению с чистопородными сверстниками имели более высокие индексы груди, массы тела, костистости и уступали по индексам растянутости и перерослости (табл. 3). Установленное преимущество чистопородных животных над гибридами $\mathrm{F}_{1}, \mathrm{~F}_{3}$ и $\mathrm{F}_{4}$ по грудному индексу, индексам растянутости и перерослости сохранялось в возрасте 42 сут и 3 мес. При этом по индексам костистости и массы тела наблюдалась обратная тенденция: выявленные в возрасте 6 сут различия в дальнейшем нивелировались.

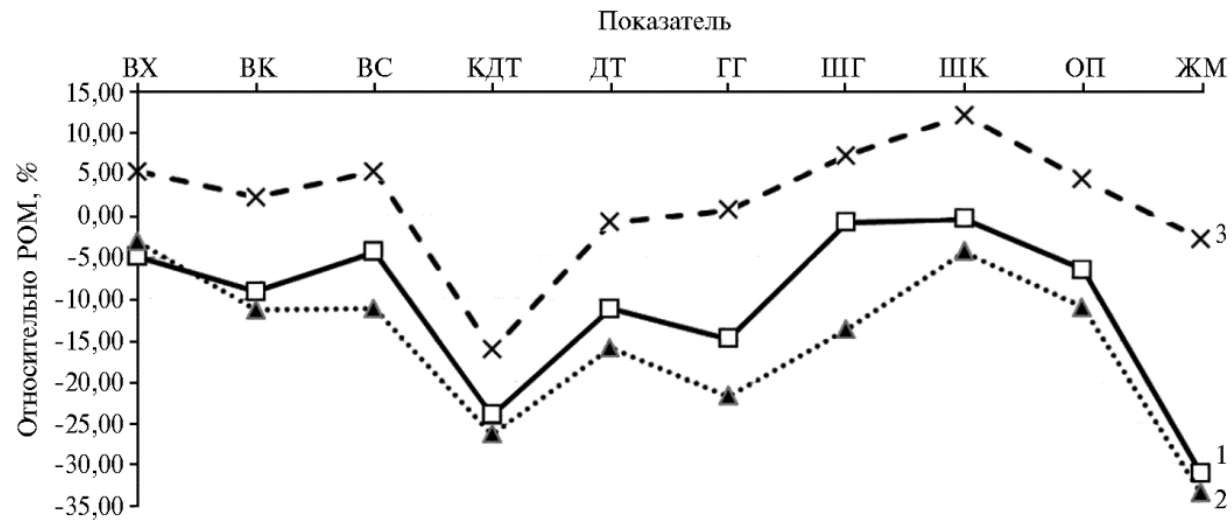

Рис. 1. Экстерьерный профиль межвидовых 3-месячных гибридов разных поколений от спаривания архара (Ovis ammon) (AРX) с романовскими овцами (O. aries) (POM) в сравнении со сверстниками романовской породы: 1 - 1/2 POM 1/2 APX, 2 - 3/8 POM 5/8 APX, 3 - 7/16 POM 9/16 АРХ; ВХ - высота в холке, см; ВК - высота в крестце, см; ВС - высота спины, см; КДТ косая длина туловища, см; ДТ - длина тела, см; ШГ - ширина груди, см; ШК - ширина крестца, см; ГГ - глубина груди, см; ОП - обхват пясти, см; ЖМ - живая масса, кг (ФИЦ животноводства - ВИЖ им. академика Л.К. Эрнста, 2019-2020 годы).

3. Индексы телосложения ягнят романовской породы (Ovis aries) (РОM) и гибридов разной кровности от спаривания романовских овец с архаром (O. ammon) (AРX) в зависимости от возраста ( $M \pm \mathrm{SEM}$, ФИЦ животноводства ВИЖ им. академика Л.К. Эрнста, 2019-2020 годы)

\begin{tabular}{|c|c|c|c|c|}
\hline \multirow{2}{*}{ Показатель } & \multicolumn{4}{|c|}{ Генотип } \\
\hline & POM & $1 / 2$ POM $^{1} / 2$ APX & $3 / 8$ POM 5/8 APX & 7/16 POM 9/16 APX \\
\hline \multicolumn{5}{|c|}{ Возраст 6 сут } \\
\hline Грудной индекс & $51,85 \pm 1,91$ & $53,88 \pm 2,44$ & $58,48 \pm 2,60^{* a}$ & $56,99 \pm 1,99$ \\
\hline Индекс растянутости & $80,34 \pm 2,02^{*} \mathrm{cb}$ & $73,19 \pm 2,57$ & $75,74 \pm 2,75$ & $71,86 \pm 2,10$ \\
\hline Индекс перерослости & $100,63 \pm 0,71^{*} \mathrm{cb}$ & $96,92 \pm 0,91$ & $99,29 \pm 0,97$ & $96,96 \pm 0,74$ \\
\hline Индекс длинноногости & $65,28 \pm 0,88$ & $64,27 \pm 1,13$ & $66,09 \pm 1,21$ & $64,99 \pm 0,92$ \\
\hline Индекс костистости & $10,99 \pm 1,23$ & $13,50 \pm 1,57$ & $13,30 \pm 1,68$ & $12,92 \pm 1,28$ \\
\hline Индекс массы тела & $7,77 \pm 0,62$ & $8,49 \pm 0,80$ & $9,52 \pm 0,85$ & $10,26 \pm 0,65^{* a}$ \\
\hline \multicolumn{5}{|c|}{ Возраст 42 сут } \\
\hline Грудной индекс & $58,90 \pm 2,43$ & $55,55 \pm 3,05$ & $58,40 \pm 3,60$ & $59,13 \pm 2,33$ \\
\hline Индекс растянутости & $87,21 \pm 1,25^{*} \mathrm{cbd}$ & $74,05 \pm 1,59$ & $70,73 \pm 1,85$ & $71,08 \pm 1,19$ \\
\hline Индекс перерослости & $100,09 \pm 1,05$ & $99,10 \pm 1,31$ & $101,05 \pm 1,56$ & $99,45 \pm 1,00$ \\
\hline Индекс длинноногости & $65,01 \pm 1,53$ & $63,90 \pm 1,92$ & $65,95 \pm 2,27$ & $63,09 \pm 1,47$ \\
\hline Индекс костистости & $12,04 \pm 0,37$ & $11,98 \pm 0,47$ & $12,27 \pm 0,56$ & $11,85 \pm 0,36$ \\
\hline Индекс массы тела & $20,28 \pm 1,17$ & $18,29 \pm 1,47$ & $17,50 \pm 1,74$ & $19,64 \pm 1,12$ \\
\hline \multicolumn{5}{|c|}{ Возраст 3 м ес } \\
\hline Грудной индекс & $53,87 \pm 1,90$ & $62,47 \pm 2,70$ & $58,82 \pm 2,32$ & $56,90 \pm 2,33$ \\
\hline Индекс растянутости & $93,46 \pm 2,04$ & $75,94 \pm 2,88$ & $72,00 \pm 2,46$ & $75,38 \pm 2,49$ \\
\hline Индекс перерослости & $102,11 \pm 0,95$ & $98,49 \pm 1,34$ & $94,00 \pm 3,30$ & $99,65 \pm 1,16$ \\
\hline Индекс длинноногости & $58,32 \pm 1,24$ & $62,20 \pm 1,76$ & $66,00 \pm 1,95^{* a}$ & $59,85 \pm 1,52$ \\
\hline Индекс костистости & $12,13 \pm 0,20$ & $11,82 \pm 0,28$ & $11,00 \pm 0,69$ & $11,87 \pm 0,24$ \\
\hline Индекс массы тела & $29,83 \pm 2,49$ & $24,80 \pm 3,52$ & $18,29 \pm 8,66$ & $30,98 \pm 3,05$ \\
\hline \multicolumn{5}{|c|}{$\begin{array}{l}\text { П р и м е ч а н и е. Обозначение сравниваемых групп животных: a - романовская порода; } \mathrm{b}-\text { гибриды }{ }^{7} / 16 \\
\text { РОМ 9/16 АРХ; с - гибриды } 1 / 2 \text { РОМ } 1 / 2 \text { АРХ; } \mathrm{d}-\text { гибриды } 3 / 8 \text { POM } 5 / 8 \text { APX. } \\
\text { * Различия между сравниваемыми группами статистически значимы при } \mathrm{p}<0,05 .\end{array}$} \\
\hline
\end{tabular}

Следует также отметить, что гибридные животные по сравнению с чистопородными особями характеризовались более высоким показателем 
индекса длинноногости, что характерно для архара. Преимущество гибридов $\mathrm{F}_{1}, \mathrm{~F} 3$ и $\mathrm{F} 4$ над чистопородными животными в возрасте 3 мес по этому показателю достигало соответственно $6,12(\mathrm{p}<0,05)$ и $3 \%$.

На основании экстерьерных показателей чистопородных овец романовской породы и их межвидовых гибридов с архаром разных поколений была выполнена иерархическая классификация. Установлено, что межвидовые гибриды с кровностью по архару $1 / 2$ и $5 / 8$ группировались в один кластер. Гибриды с кровностью по архару $9 / 16$ и чистопородные животные романовской породы образовали отдельные кластеры (рис. 2).

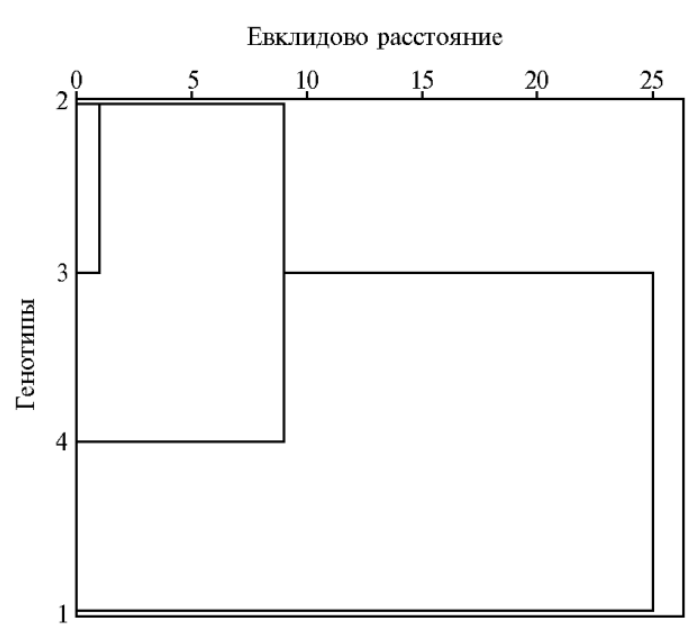

Рис. 2. Результаты иерархического анализа межвидовых гибридов разных поколений от спаривания архара (Ovis ammon) (АРХ) с овцами романовской породы (O. aries) и ягнят романовской породы $(\mathrm{POM}): 1-$ романовская порода, 2 - 3/8 POM 5/8 APX, $3-1 / 2$ POM $1 / 2$ APX, $4-7 / 16$ РОМ $9 / 16$ АРХ (ФИЦ животноводства - ВИЖ им. академика Л.К. Эрнста, 2019-2020 годы).

Выполненное нами исследование показывает, что генотип - один из основных биотических факторов, влияющих на экстерьер овец. Воздействие этого фактора на живую массу и линейные промеры статистически значимо при $\mathrm{p}<0,001$. Морфометрическим показателям уделяется особое внимание при изучении фенотипа животных, который представляет собой совокупность определенных генотипом свойств, присущих индивидууму на определенной стадии развития. Морфологические различия, основанные на общем типе телосложения, морфометрических параметрах или необычных анатомических формах, используются для идентификации, сравнения и классификации видов и групп, выявления неопознанных таксонов, неизвестных гибридов, определения мутаций, приводящих к изменениям (28). Морфологическое описание - важнейший составляющий элемент характеристики породы и селекционной формы (29) и может быть использовано для их идентификации и классификации (30).

Длительное время основным признаком классификации пород сельскохозяйственных животных, особенно овец, служила окраска шерсти (31). C. Eastham с соавт. (32) в своих исследованиях использовали морфометрические показатели для идентификации нескольких видов соколов и их гибридов. Гибриды и исходные виды группировались в самостоятельные кластеры. В наших исследованиях гибридные животные по индексам телосложения также выделялись в отдельные кластеры, расстояния между которыми определялись генотипом гибридов.

Полученные нами результаты соответствуют данным других авторов, которые предлагают применять экстерьерные показатели для идентификации породы и селекционной формы (6-8).

Таким образом, межвидовые гибриды архара с овцами романовской породы по экстерьерным показателям унаследовали некоторые экстерьерной особенности архара и отличаются от исходной материнской породы. По сравнению с чистопородными животными они характеризуются более компактным телосложением, имеют более сжатую прямоугольную форму 
туловища. Это выражается в снижении у гибридных животных по сравнению с чистопородными сверстниками показателей косой длины туловища и индекса растянутости в зависимости от кровности соответственно на 1420 и 18-22 \% (p < 0,05). Полученные нами данные подтверждают, что экстерьерные показатели могут быть использованы для предварительной идентификации гибридных особей, сокращая в ряде случаев затраты на дорогостоящие геномные исследования.

\section{Л ИТ Р РАТ У РА}

1. Улимбашев М.Б., Кулинцев В.В., Селионова М.И., Улимбашева Р.А., Абилов Б.Т., Алагирова Ж.Т. Рациональное использование генофонда ценных пород животных с целью сохранения биологического разнообразия. Юг России: экология, развитие, 2018, 13(2): 165183 (doi: 10.18470/1992-1098-2018-2-165-183).

2. Марзанов Н.С., Апишева Ф.К., Марзанова Л.К., Саморуков Ю.В., Кертиев Р.М. Современная характеристика понятия «порода». Сельскохозяйственная биология, 2007, 42(6): 16-23.

3. Столповский Ю.А. Популяционно-генетические основы сохранения генофондов доместицированных видов животных. Вавиловский журнал генетики и селекции, 2013, 17(4-2): 900-915.

4. Yunusa A.J., Salako A.E., Oladejo O.A. Morphometric characterization of Nigerian indigenous sheep using multifactorial discriminant analysis. International Journal of Biodiversity and Conservation, 2013, 5(10): 661-665 (doi: 10.5897/IJBC2013.0592).

5. Salako A.E., Ngere L.O. Application of multifactorial discriminant analysis in the morphometric structural differentiation of the West African Dwarf (WAD) and Yankasa sheep in the South West Nigeria. Nigerian Journal of Animal Production, 2002, 29(1): 163-167.

6. Legaz E., Cervantes I., Pérez-Cabal M.A., de la Fuente L.F., Mártinez R., Goyache F., Gutiérrez J.P. Multivariate characterization of morphological traits in Assaf (Assaf.E) sheep. Small Ruminant Research, 2011, 100(2-3): 122-130 (doi: 10.1016/j.smallrumres.2011.06.005).

7. Yadav D.K., Arora R., Jain A. Classification and conservation priority of five Deccani sheep ecotypes of Maharashtra, India. PLoS ONE, 2017, 12(9): e0184691 (doi: 10.1371/journal.pone.0184691).

8. Sahana G., Jain A., Maity S.B. Characterization and evaluation of Jalauni sheep. Animal Genetic Resources Information, 2004, 34: 67-73 (doi: 10.1017/S1014233900001747).

9. Gizaw S., Van Arendonk J.A.M., Komen H., Windig J.J., Hanotte O. Population structure, genetic variation and morphological diversity in indigenous sheep of Ethiopia. Animal Genetics, 2007, 38(6): 621-628 (doi: 10.1111/j.1365-2052.2007.01659.x).

10. Yakubu A., Ibrahim I.A. Multivariate analysis of morphostructural characteristics in Nigerian indigenous sheep. Italian Journal of Animal Science, 2011, 10(2): e17 (doi: 10.4081/ijas.2011.e17).

11. Денискова Т.Е., Селионова М.И., Гладырь Е.А., Доцев А.В., Бобрышова Г.Т., Костюнина О.В., Брем Г., Зиновьева Н.А. Изменчивость микросателлитов в породах овец, разводимых в России. Сельскохозяйственная биология, 2016, 51(6): 801-810 (doi: 10.15389/agrobiology.2016.6.801 rus).

12. Stojiljkovi M., Stevanovi O., Ivanov S., Drobnjak D., Urosevi M., Trailovi R. Morphometrical characterisation of Karakachan sheep from Stara planina, Serbia. Bulgarian Journal of Agricultural Science, 2015, 21(6): 1278-1284.

13. Otoikhian C.S.O., Otoikhian A.M., Akporhuarho O.P., Isidahomen C. Correlation of body weight and some body measurement parameters in Ouda sheep under extensive management system. African Journal of Agricultural Research, 2008, 3: 129-133.

14. Abdel-Moneim A.Y. Use of live body measurements for prediction of body and carcass cuts weights in three Egyptian breeds of sheep. Egyptian Journal of Sheep and Goat Sciences, 2009, 4(2): $17-32$.

15. Jimmy S., David M., Donald K.R., Dennis M. Variability in body morphometric measurements and their application in predicting live body weight of Mubende and Small East African goat breeds in Uganda. Middle-East Journal of Scientific Research, 2010, 5(2): 98-105.

16. Khargharia G., Kadirvel G., Kumar S., Doley S., Bharti P.K., Das M. Principal component analysis of morphological traits of Assam hill goat in eastern Himalayan India. The Journal of Animal and Plant Sciences, 2015, 25(5): 1251-1258.

17. Rogić B., Važić B., Jovanović S., Stamenković-Radak M., Savić M., Ravić I. Investigations of variability of morphometric characteristics in Busa and Gatacko cattle in order to preserve autochthonous genome. Veterinarski glasnik, 2011, 65(1-2): 61-69 (doi: 10.2298/VETGL1102061R).

18. Sowande O.S., Sobola O.S. Body measurements of west African dwarf sheep as parameters for estimation of live weight. Tropical Animal Health and Production, 2008, 40(6): 433-439. (doi: 10.1007/s11250-007-9116-z). 
19. Marković B., Dovč P., Marković M., Radonjić D., Adakalić M., Simčič M. Differentiation of some Pramenka sheep breeds based on morphometric characteristics. Arch. Anim. Breed., 2019, 62: 393402 (doi: 10.5194/aab-62-393-2019).

20. DekhiliM. A morphometric study of sheep reared in north-east Algerian. Arch. Zootec., 2014, 63(244): 623-631 (doi: 10.4321/S0004-05922014000400006).

21. Дмитриева Т.О. Характеристика экстерьерных особенностей молодняка катумской породы овец при рождении. Евразийский Союз Ученых, 2019, 19(66): 9-11 (doi: 10.31618/esu.24139335.2019.1.66.294).

22. Babale D.M., Hussein A.U., Gworgwor Z. Relationship between liveweights, linear body measurements and cost prices of small ruminants sold in and around mubi environs, adamawa state, Nigeria. J. Dairy Vet. Anim. Res., 2018, 7(6): 273-277 (doi: 10.15406/jdvar.2018.07.00226).

23. Chniter M., Hammadi M., Khorchani T., Krit R., Lahsoumi B., Sassi M.B., Nowak R., Hamouda M.B. Phenotypic and seasonal factors influence birth weight, growth rate and lamb mortality in D'man sheep maintained under intensive management in Tunisian oases. Small Ruminant Research, 2011, 99(2-3):166-170 (doi: 10.1016/j.smallrumres.2011.03.046).

24. Koyuncu M., Uzun S.K. Growth performance of Karacabey Merino and Kivircik lambs under semiintensive management in Turkey. Small Ruminant Research, 2009, 83(1-3): 64-66 (doi: 10.1016/j.smallrumres.2009.03.001).

25. Estrada-Angulo A., Castro-Pérez B.I., Urías-Estrada J.D., Ríos-Rincón F.G., Arteaga-Wences Y.J., Barreras A., López-Soto M.A., Plascencia A., Zinn R.A. Influence of protein level on growth performance, dietary energetics and carcass characteristics of Pelibuey $\times$ Katahdin lambs finished with isocaloric diets. Small Ruminant Research, 2018, 160:59-64 (doi: 10.1016/j.smallrumres.2018.01.012).

26. Georges M. Recent progress in livestock genomics and potential impact on breeding programs. Theriogenology, 2001, 55(1): 15-21 (doi: 10.1016/S0093-691X(00)00442-8).

27. Rosov A., Gootwine E. Birth weight and pre- and postweaning growth rates of lambs belonging to the Afec-Assaf strain and its crosses with the American Suffolk. Small Ruminant Research, 2013, 113(1): 58-61 (doi: 10.1016/j.smallrumres.2013.02.015).

28. Park I.S., Woo S., Song Y.C., Cho S. Effects of starvation on morphometric characteristics of olive flounder, Paralichthys olivaceus. Ichthyol. Res., 2007, 54(3): 297 (doi: 10.1007/s10228-0070404-4).

29. Popoola M.A., Oseni S.O. Multifactorial discriminant analysis of cephalic morphology of Indigenous breeds of sheep in Nigeria. Slovak J. Anim. Sci., 2018, 51(2): 45-51.

30. Gizaw S., Van Arendonk J.A.M., Komen H., Windig J.J., Hanotte O. Population structure, genetic variation and morphological diversity in indigenous sheep of Ethiopia. Animal Genetics, 2007, 38(6): 621-628 (doi: 10.1111/j.1365-2052.2007.01659.x).

31. Koseniuk A., Ropka-Molik K., Rubiś D., Smołucha G. Genetic background of coat colour in sheep. Arch. Anim. Breed., 2018, 61(2): 173-178 (doi: 10.5194/aab-61-173-2018).

32. Eastham C., Nicholls M. Morphometric analysis of large Falco species and their hybrids with implications for conservation. Journal of Raptor Research, 2005, 39(4): 386-393.

ФГБНУ ФИЦ животноводства -

ВИЖ им. академика Л.К. Эрнста,

142132 Россия, Московская обл., г.о. Подольск, пос. Дубровицы, 60,

e-mail: baylar1@yandex.ru $\bowtie$, natavolkova@inbox.ru, vugarbagirov@mail.ru,

n_zinovieva@mail.ru
Поступила в редакиию 17 августа 2020 года

Sel'skokhozyaistvennaya biologiya [Agricultural Biology], 2020, V. 55, № 6, pp. 1139-1147

\title{
IDENTIFICATION OF INTERSPECIFIC HYBRIDS ARGALI (Ovis ammon) AND DOMESTIC SHEEP (Ovis aries) OF DIFFERENT GENERATIONS BY EXTERIOR INDICATORS
}

\author{
B.S. Iolchiev ${ }^{凶}$, N.A. Volkova, V.A. Bagirov, N.A. Zinovieva
}

Ernst Federal Science Center for Animal Husbandry, 60, pos. Dubrovitsy, Podolsk District, Moscow Province, 142132 Russia, e-mail: baylar1@yandex.ru ( $₫$ corresponding author), natavolkova@inbox.ru, vugarbagirov@mail.ru, n_zinovieva@mail.ru

ORCID:

Iolchiev B.S.orcid.org/0000-0001-5386-726

Volkova N.A. orcid.org/0000-0001-7191-3550

Bagirov V.A. orcid.org/0000-0001-8385-2433

The authors declare no conflict of interests

Zinovieva N.A. orcid.org/0000-0003-4017-6863

Acknowledgements:

Supported financially by Russian Science Foundation, grant No. 18-16-00079 and the Ministry of Science and Higher Education of the Russian Federation, theme no. AAAA-A18-118021590132-9.

Received August 17, 2020

doi: 10.15389/agrobiology.2020.6.1139eng 


\begin{abstract}
When creating new breeds and breeding forms, various breeding methods are used, including hybridization. For a long time in the Ernst Federal Science Center for Animal Husbandry, work is underway to use the genetic resources of wild species, in particular argali (Ovis ammon), to obtain interspecific hybrids with domestic sheep (Ovis aries) in the framework of creating new breeding forms and studying the biological characteristics of certain species of the genus Ovis. This raises the question of identifying the obtained interspecific hybrids. Along with conducting expensive studies on the genotyping of such animals, it is of interest to use informative phenotypic indicators characteristic of hybrid individuals. In this work, for the first time, comparative results of differentiation by exterior characteristics of interspecific hybrids of different generations from mating argali with sheep are presented. Romanov breed and original parental forms. The possibility of using exterior indicators for preliminary identification of hybrid individuals without expensive genomic studies was confirmed. Hybridization in the second and subsequent generations resulted in the splitting of hybrid individuals by genotype and phenotype. The work aimed at comparing morphometric parameters of the purebred Romanov sheep and their interspecific hybrids with argali and to reveal informative exterior indicators for identifying hybrid individuals. The lambs of Romanov breed $(n=20)$ and the interspecific hybrids $1 / 2$ Romanov sheep $1 / 2$ argali $\left(\mathrm{F}_{1}, n=12\right), 3 / 8$ Romanov sheep $5 / 8$ argali $\left(\mathrm{F}_{3}, n=17\right)$, and $7 / 16$ Romanov sheep $9 / 16$ argali $(\mathrm{F} 4, n=18)$ were reared from birth under the conditions of vivarium (the Ernst Federal Science Center for Animal Husbandry, 2019-2020). The following measurements were recorded: height in withers, height at the sacrum, back height, oblique body length, body length, chest width, sacrum width, chest depth, metacarpal girth. Linear measurements were taken at the age of 6 , 42 days, and 3 months using a measuring tape, tape measure, and a measuring compass. The animals were weighed on an electronic balance. To assess the development of animals on the basis of weight and linear measurements, the body indices were calculated: long-legged index, elongation index, overgrowth index, breast index, bone index, body mass index. The SPSS v.23 software was used for statistical analysis. As a factor influencing the linear measurements of lambs, the breed of individuals was chosen. Hybrid animals at the age of 3 months in comparison with purebred individuals of the Romanov breed had higher indicators of the long-legged index, which is typical for argali. The advantage of $F_{1}, F_{3}$ and $F_{4}$ hybrids over purebred animals for this indicator was 4,8 and $2 \%$, respectively. At the same time, hybrids $\mathrm{F}_{1}, \mathrm{~F}_{3}$, and $\mathrm{F}_{4}$ had a more compressed rectangular body shape, therefore, they were inferior to purebred lambs in terms of elongation index, respectively, by 18, 22 and $18 \%(\mathrm{p}<0.05)$. Differences were established between purebred and hybrid animals in linear and latitudinal measurements. The advantage of purebred sheep over F1, F3 and F4 hybrids was 18,20 and $14 \%$ in oblique body length, 35, 33 and $20 \%(\mathrm{p}<0.05)$ in chest width, and 17,19 and $7 \%$ $(\mathrm{p}<0.05)$ in chest depth. Hierarchical classification of hybrids and purebred animals according to the exterior characteristics, it showed that interspecific hybrids with $1 / 2$ and $5 / 8$ argali bloodlines were grouped in one cluster. Hybrids with $9 / 16$ bloodiness according to the argali and purebred Romanov sheep formed separate clusters. The results obtained confirm that the exterior parameters can be used for preliminary identification of hybrid individuals, in some cases reducing the cost of expensive genomic studies.
\end{abstract}

Keywords: interspecific hybrids, Ovis ammon, argali, Ovis aries, Romanov breed, exterior. 